\title{
TEORIA DO CONFLITO EM MAQUIAVEL E O AGONISMO DE CHANTAL MOUFFE: POSSÍVEIS CONEXÕES
}

\author{
Karen Elena Costa Dal Castel ${ }^{1,2}$
}

\begin{abstract}
Resumo: A pesquisa tem por proposta fazer uma análise acerca de duas categorias: o conflito em Maquiavel, no sentido de um confronto de desejos como sendo algo saudável para a república e o modelo agonístico de democracia demonstrado por Chantal Mouffe que está atrelado a ideia de transformar o inimigo em adversário. Pretende-se verificar em que medida essas ideias se aproximam e/ou se afastam em seus significados. A metodologia baseia-se no aporte teórico de alguns autores que vem trabalhando essa temática, como José Luiz Ames e Luis Felipe Miguel, bem como autores que trabalham a ideia de conflito em Maquiavel. Por fim, pretende-se mostrar que existem elementos da teoria maquiaveliana presentes nas categorias analíticas elucidadas por Chantal Mouffe, que podem contribuir para o debate das teorias da democracia.
\end{abstract}

Palavras-chave: Conflito. Agonismo. Maquiavel. Mouffe.

\section{INTRODUÇÃO}

A democracia tem sido nos últimos anos a grande preocupação de uma forma geral dos países que buscam caminhar junto ao desenvolvimento político, social e econômico. Tem sido a palavra-chave, o grande objetivo das nações que buscam uma igualdade política. Como exemplo dessa repercussão tem-se as últimas manifestações no Egito em $2011^{3}$, de uma população que viveu por muitos anos em uma ditadura, que foi às ruas clamar por democracia. Pretende-se, nesse contexto, pensar os rumos da democracia que é hoje associada a algo bom e puro pois tem sido a única forma de governo compatível

1 Doutoranda do Programa de Pós-Graduação de Sociologia Política da Universidade Federal de Santa Catarina PPGSP/UFSC. E-mail: karendalcastel@gmail.com

2 Versão anterior deste artigo foi apresentada no $10^{\circ}$ Encontro da ABCP e no II Colóquio Maquiavel - I Encontro Maquiavel: Política e Literatura, promovido pela UFSC. Agradeço o convite do colóquio para publicá-lo na revista Gavagai.

3 A Revolução Egípcia, também chamada de Revolução do Nilo, Revolução de Lótus e Dias de Fúria, teve seu início no dia 25 de janeiro de 2011 terminando em 11 de fevereiro de 2011. As revoltas contra o regime ditatorial e o governante Hosni Mubarak que estava no poder há 30 anos, duraram 18 dias até sua renúncia, deixando mais de 300 mortos e 5 mil feridos. 
com a finalidade de alcançar o bem comum ${ }^{4}$.

Nesse sentido, a contribuição dessa pesquisa se dá em buscar um diálogo de uma teoria recente elucidada por Chantal Mouffe, que tem por ideia principal pensar o agonismo democrático com o republicanismo conflituoso de Maquiavel, onde a chave é provocar o dissenso, incitar que ideias opostas de desejos opostos interajam no campo político afim amenizar os humores divergentes de grandes e povo. Humores esses que são inconciliáveis, incompatíveis. Posto isso, nota-se uma relevância para um melhor entendimento da democracia contemporânea que, o dissenso proporciona possibilidades de diálogo que não são possíveis no consenso.

Assim sendo, esse artigo se dividirá em três partes: na primeira delas, delinear-se-á acerca da teoria do conflito em Maquiavel, a partir de suas três obras principais. No segundo momento far-se-á uma análise da teoria agonística de Chantal Mouffe, baseada principalmente em um de seus principais trabalhos e possivelmente principal contribuição para o campo da Política que vem a ser Hegemonia e estratégia socialista e seu artigo Por um modelo agonístico de democracia. Por fim atrelar alguns pontos dessas duas teorias, analisando suas contribuições para um melhor entendimento da democracia contemporânea.

\section{A TESE DO CONFLITO EM MAQUIAVEL}

Chamar-se-á conflito positivo em Maquiavel aquele que em dado contexto propõe de forma saudável o dissenso entre as "classes", entre nobres e servos; entre ricos e pobres; entre grandes e povo. Há uma interpretação "mais ou menos consensual entre os neorrepublicanos sobre o papel positivo que Maquiavel atribui ao conflito social, compreendendo-o como a causa da liberdade" (SILVA, 2013 p. 55). Conflito negativo é todo aquele que se

4 Há discussões em torno do significado de bem comum na teoria maquiaveliana, como sendo uma finalidade partilhada por todos, rebatendo a ideia de unificação dos desejos que seria incompatível com a teoria do conflito, pois que se há desejos opostos eles não podem querer o mesmo fim, que seria a busca por um bem comum da sociedade. Essa questão pretende-se debater em outro momento de forma aprofundada, pois que para alguns autores como Ames (2012) "Maquiavel rompe com essa representação do bem comum: não somente nega a possibilidade de um objeto determinável (um "bem" comum), mas também que possa ser "um" (...) a crítica de Maquiavel à idéia de bem comum não é a negação do bem geral (...) é a afirmação de que ninguém pode se apropriar do bem público, nenhum grupo pode falar dele como coisa sua, nem mesmo o governo do Estado. Não é, portanto uma versão originária do lema liberal da "pluralidade de bens", e sim a afirmação da radical indeterminação do bem comum como algo que não se deixa representar nem apropriar (p. 231). 
deteriorar, se corromper, se desvirtuar do seu ideal conflituoso. E não importa em Maquiavel quem praticou a corrupção. Ela é mais fácil de ocorrer entre os que desejam o poder. Mas ela também pode ocorrer naquele que deseja não ser oprimido, naquele que deseja ser o guardião da liberdade: o povo, pois que,

A equiparação do desejo do povo ao desejo dos grandes é, pois, a causa da corrupção e da ruína da liberdade em Florença (...) o desejo do povo não pode conduzir o corpo político à liberdade porque ele deseja o mesmo que os grandes: tomar o poder para comandar e oprimir (...). É o fim da diferença dos desejos. O povo, ao pretender ficar sozinho no poder, produz a identificação de seu humor ao dos grandes. Restando apenas um dos dois humores, ele se impõe sobre todo o corpo político. É o fim da liberdade. (WINTER, 2011, p. 67)

Assim, povo desejar o mesmo que grandes, é terminar com as ideias antagônicas, com as divergências, com os dissensos saudáveis à liberdade e dar origem a um tipo de governo nocivo à mesma: a tirania. Em História de Florença, o contexto analisado por Maquiavel é a ruína de uma república. Logo, o possível fim da liberdade, tendo em vista que ocorre a igualdade de desejos de povo e grandes, afunilando esses desejos antes antagônicos e necessários para manter a liberdade em um só desejo de opressão, poder, dominação.

No republicanismo não é considerada a liberdade do indivíduo, mas sim de um corpo social participativo nas coisas públicas, exercendo a cidadania. No pensamento republicano de Maquiavel, o conflito é parte central para a concepção de liberdade. Porém deve-se ter cautela em relação a tese do conflito pois "é preciso evitar compreendê-la de forma genérica e em termos exclusivamente normativos, como se Maquiavel estivesse a prescrever o conflito de classes e a realizar um elogio incondicional desses conflitos" (SILVA, 2013, p. 44). Os conflitos são saudáveis na medida em que as demandas populares são atendidas. Maquiavel fala de conflito saudável à república no sentido de dissenso. Conflitos como as guerras civis são nocivos à liberdade.

República desde Roma implica liberdade dos povos. Segundo Bignotto, "para se compreender o sentido da liberdade, é preciso entender o sentido da república" (BIGNOTTO, 1991, p. 75). A forma republicana perfeita de Maquiavel é aquela em que há a desunião entre a plebe e o senado, ou seja, aquela forma de governo que torna possível e saudável os conflitos. Esses são a causa da liberdade. Das duas vertentes de liberdade (positiva e negativa) Philip Pettit elucidou uma terceira: a liberdade como não-dominação, sendo essa conceituação a que se considera a mais semelhante aos ideais de liberdade em Maquiavel. 
Maquiavel afirma no livro primeiro dos Discursos que "em toda república há dois humores diferentes, o do povo e o dos grandes, e que todas as leis que se fazem em favor da liberdade nascem da desunião deles" (Discursos, I, 4, p.22). Os humores na linguagem maquiaveliana são os desejos e esses são diferentes entre o povo e os grandes, pois um deseja não ser oprimido e o outro deseja comandar e oprimir. A liberdade é então, citando a explicação de Bignotto, o resultado dos conflitos.

Dessa forma, da desunião é que nascerá a liberdade para Maquiavel. O que vem a ser um tanto contraditório para alguns autores que buscam promover a união dos povos com seus representantes, bem como o acordo entre eles para que a igualdade entre povos seja finalmente alcançada, é para Maquiavel a pura incoerência, por dois motivos: primeiro porque ele é contra o pensamento de sociedades ideais e perfeitas, onde a igualdade reinará. Para Maquiavel, essas sociedades nunca existiram, são utopias, por isso discorda de Aristóteles, Platão e todos os outros pensadores desse gênero; e segundo porque Maquiavel acredita que não se tem liberdade enquanto não existir a luta entre as diferenças, visto que são as desavenças, os conflitos que farão surgir a liberdade republicana. Dessa forma, os conflitos são necessários para manter os desiguais em igualdade, para fazê-los lutar pela sua emancipação e não aceitar as regras do outro, mas sim fazer leis que beneficiem a maioria.

Assim sendo, de que conflitos Maquiavel refere-se como saudáveis para a liberdade, já que uma sociedade desigual onde é permitido um principado, propicia um governo de um só? Essa questão do conflito gera alguns pressupostos que podem levar a interpretações equívocas de seu pensamento como, por exemplo, acreditar que por Maquiavel ser favorável ao conflito como crucial para a existência e permanência da liberdade, ele incitaria os conflitos civis, como guerras e corrupções em geral. A tese do conflito está atrelada aos desejos antagônicos dos sujeitos povo e grandes. Dessa forma, entende-se em Maquiavel, que esses humores são incompatíveis dada a necessidade de se manter a liberdade republicana, um desejo não pode se igualar ao outro. A liberdade é o conflito, no sentido de desarmonia na cidade. E esse conflito é saudável e necessário em Maquiavel.

A liberdade existe enquanto o conflito de desejos. Ela só é possível na medida em que os confrontos opostos de povo e grandes possam coexistir na polis. É nesse sentido, que a liberdade republicana existe em Maquiavel. A liberdade positiva é entendida pelo conflito de desejos. E o mesmo é benéfico enquanto garantia de participação política do povo; enquanto esse tem o direito 
de decisão nas coisas públicas. Enquanto o povo desejar não ser dominado e os grandes desejarem dominar, a liberdade estará garantida. O risco que se corre é o povo desejar o poder ou os grandes dominarem o povo. Em ambos os casos perde-se o sentido da liberdade, resultando em uma tirania, em um conflito negativo corrompido pela ganância do povo e dos grandes. Dessa forma, o conflito positivo é necessário em Maquiavel. Ele forma um cenário desarmônico, uma sociedade com desejos opostos e nisso se sustenta a liberdade. É nessa desarmonia que ela encontra o seu fundamento. Desarmonia essa que está presente no agonismo democrático de Chantal Mouffe.

\section{O AGONISMO DE MOUFFE}

A proposta teórica de Chantal Mouffe, que está longe de ser uma estrutura política normativa ${ }^{5}$, teve início na obra em conjunto com Ernesto Laclau, intitulada Hegemonia e estratégia socialista: até uma radicalização da democracia (1987). A partir daí suas teorias de um modelo agonístico de democracia tiveram início, havendo também uma diferença de pensamentos entre Mouffe e Laclau, conforme Mendonça (2010):

após a publicação de Hegemony and socialist strategy, em 1985, por Ernesto Laclau e Chantal Mouffe, parece ter havido uma divisão do trabalho, pelo menos tácita, entre ambos os autores, no sentido da divulgação dos seus principais aspectos teóricos e epistemológicos. (MENDONÇA, 2010, p. 479)

Diferenças à parte, uma de suas principais contribuições para a Teoria Política vem a ser a ideia de um modelo agonístico de Democracia. O que para alguns críticos esse modelo se torna incompleto:

Mouffe não apresenta propriamente um modelo teórico visando superar o deliberacionismo, o qual ela considera como sendo hegemônico no atual contexto da teoria política. Ela se resume a repetir, aí sim, seu princípio agônico no contexto democrático. Trata-se, portanto, de um modelo incompleto. (MENDONÇA, 2010, p. 495)

Críticas à parte, pois não é o objetivo desse trabalho aprofundar as limitações de Mouffe, mas sim extrair de sua teoria, contribuições para somar à teoria do conflito de Maquiavel. Para a autora, o que está em jogo na fidelidade

5 "Parte-se do pressuposto, portanto, de que o mesmo, na verdade, revela-se tão somente um princípio, estando muito aquém de um modelo político normativo estruturado" (MENDONÇA, 2010, p. 480). 
a instituições democráticas é a possibilidade de criação de cidadãos democráticos. Ela desenvolve a visão de que indivíduos da democracia só serão possíveis com a multiplicação de instituições, discursos, formas de vida que fomentem a identificação com valores democráticos.

Para Mouffe, é necessário um modelo democrático capaz de apreender a natureza do político e a questão do poder e do antagonismo no centro. De acordo com a abordagem deliberativa, quanto mais democrática uma sociedade, menos o poder será constitutivo das relações sociais. A questão principal para a política democrática não é como eliminar o poder, mas ter formas de poder mais compatíveis com valores democráticos. A autora chama seu modelo de pluralismo agonístico, enfatizando reconhecer a sua dimensão conflitual. Ela faz a distinção entre "política" e o "político":

Por "o político" refiro-me à dimensão do antagonismo inerente às relações humanas, um antagonismo que pode tomar muitas formas e emergir em diferentes tipos de relações sociais. A "política", por outro lado, indica o conjunto de práticas, discursos e instituições que procuram estabelecer uma certa ordem e organizar a coexistência humana em condições que são sempre conflituais porque são sempre afetadas pela dimensão do "político". (MOUFFE, 2005, p. 20)

Assim, ela explica que a "política" consiste em domesticar a hostilidade e em tentar conter o potencial antagonismo que existe nas relações humanas. A política busca a criação da unidade em um contexto de conflitos e diversidade; está ligada à criação de um 'nós' em oposição a um 'eles'. O ponto crucial é estabelecer essa discriminação nós-eles de um modo compatível com a democracia.

o propósito da política democrática é construir o "eles" de tal modo que não sejam percebidos como inimigos a serem destruídos, mas como adversários, ou seja, pessoas cujas idéias são combatidas, mas cujo direito de defender tais idéias não é colocado em questão. (MOUFFE, 2005, p. 20)

Dessa forma, tem-se que um adversário é um inimigo, mas um inimigo legítimo, com quem temos alguma base em comum em virtude de compartilhar princípios como a liberdade e a igualdade. Aceitar a visão do adversário significa passar por uma mudança radical de identidades políticas. O ideal de uma democracia pluralista não pode ser o consenso racional. Cada consenso existe como resultado temporário de uma hegemonia provisória, como estabilização do poder resultando em exclusões. Acreditar que o poder poderia ser dissolvido por meio de um debate racional e que a legitimidade poderia ser 
baseada na racionalidade pura são ilusões que colocam em risco as instituições. Mouffe acredita que o antagonismo é a luta entre inimigos e o agonismo é a luta entre adversários.

Pode-se dizer então que Mouffe tem uma clara intenção: "desde a perspectiva do 'pluralismo agonístico', o propósito da política democrática é transformar antagonismo em agonismo" (MOUFFE, 2005, p. 21), tendo o opositor não como inimigo, mas como adversário.

Ao final desse seu artigo Chantal Mouffe (2005) propõe abrir caminho para o dissenso, promover as instituições onde possa se manifestar é vital para a democracia pluralista. A abordagem agonística é a de reconhecer os limites reais de tais fronteiras e as formas de exclusão que delas decorrem, ao invés de tentar disfarçar sob as formas da racionalidade e da moralidade. Esse é o começo para uma democracia mais justa, plural e igualitária, respeitando as diferenças. E conclui:

Compreendendo a natureza hegemônica das relações sociais e identidades, nossa abordagem pode contribuir para subverter a sempre presente tentação existente nas sociedades democráticas de naturalizar suas fronteiras e "essencializar" as suas identidades. Por essa razão, ele é muito mais receptivo do que o modelo deliberativo à multiplicidade de vozes que as sociedades pluralistas contemporâneas abarcam e à complexidade de sua estrutura de poder. (MOUFFE, 2005, p. 22)

\section{CONCLUSÕES PARCIAIS DAS POSSÍVEIS CONEXÕES ENTRE CONFLITO E AGONISMO}

Existem ao menos dois cenários possíveis quando Mouffe se pergunta sobre o entendimento de uma sociedade democrática. Embora a autora não se utilize profundamente da teoria do conflito de Maquiavel para reforçar suas categorias, existem alguns pontos em comum que somados podem contribuir para pensar os desafios da democracia contemporânea. Nesse cenário Mouffe ao questionar-se sobre o que é uma sociedade democrática, ela visualiza dois contextos diferentes, em suas palavras:

É uma sociedade pacificada e harmoniosa onde as divergências básicas foram superadas e onde se estabeleceu um consenso imposto a partir de uma interpretação única dos valores comuns? Ou é uma sociedade com uma esfera pública vibrante onde muitas visões conflitantes podem se expressar e onde há uma possibilidade de escolha entre projetos alternativos legítimos? (MOUFFE, 
2003, p. 11)

Dentre essas duas possibilidades, Mouffe posiciona-se como favorável à segunda perspectiva, o que, segundo Ames (2012, p. 221) "a situa na linha de continuidade do republicanismo conflitual de Maquiavel". A grande questão é que o dissenso foi perdendo espaço para o consenso e isso vem a ser o grande mal das democracias atuais.

Mouffe cita uma das passagens centrais do pensamento de Maquiavel ao menos em um dos seus trabalhos para somar à sua ideia acerca do político, que vem a ser a questão dos humores de povo e grandes: "En el domínio de "lo político', aun vale la pena meditar acerca de la idea crucial de Maquiavelo: 'En cada ciudad podemos hallar estos dos deseos diferentes [...]” (2009, p. 14). Após a citação, ela conclui afirmando que a definição da perspectiva póspolítica é a afirmação de que entramos em uma nova era onde este antagonismo potencial desapareceu e que isso pode colocar em risco o futuro da política democrática.

Um dos problemas que dificulta na evolução das democracias é exatamente esse desaparecimento da possibilidade de existência e permanência das ideias antagônicas dos mais variados grupos étnicos, políticos e sociológicos. Essa ausência do dissenso ficou desaparecida no campo político em detrimento de uma falsa ideia de que se deve buscar sempre o consenso como sendo algo benéfico às sociedades, ou seja, há um consenso de que toda e qualquer deliberação deve ser com o objetivo supremo de buscar um equilíbrio, uma harmonia; o que para Mouffe "é sempre uma quimera" (MOUFFE apud MIGUEL, 2014, p. 14).

É do interesse dos que detém o poder, buscar um consenso e alimentar isso à população, pois que para eles isso traz benefícios, não gerando conflitos. Com esse cenário a margem para o liberalismo aumenta e as políticas públicas que visam garantia de direitos aos menos favorecidos acaba perdendo voz.

Nesse sentido, a ideia do 'político' em Mouffe vem a ser um espaço de poder, conflito e antagonismo. O que seria muito semelhante ao conflito defendido por Maquiavel onde ele coloca que: "a desunião entre plebe e senado tornou livre e poderosa a república romana” (Discursos, I, 4, p. 21). Ainda vale frisar que o capítulo quatro é, segundo Ricardo Silva, onde Maquiavel "desenvolve a tese do conflito como causa da liberdade" (SILVA, 2010, p. 50). Maquiavel assim afirma nesse capítulo: "Roma foi uma república tumultuária e tão cheia de confusão que, se a boa fortuna e a virtù militar não tivessem suprido a seus defeitos, ela teria sido inferior a qualquer outra república" (Discursos, I, 4, p. 21). Diz também que "em toda república há dois humores 
diferentes, o do povo, e o dos grandes, e que todas as leis que se fazem em favor da liberdade nascem da desunião deles" (Discursos, I, 4, p. 22).

Assim, pode-se constatar que Maquiavel considera os conflitos sociais como sendo a causa para a busca da liberdade republicana. Luis Felipe Miguel (2014) concorda com essa constatação e cita-o em seu artigo acerca do consenso e conflito na teoria democrática: "as geniais observações de Maquiavel, há cinco séculos, permanecem válidas: o conflito é o indício de que há liberdade, de que os interesses de uma parte não subjugaram inteiramente os de outra (Maquiavel, 2007, [1513])” (p. 33).

Outra constatação de proximidades da teoria do conflito de Maquiavel com as categorias de Mouffe é em relação aos desejos opostos de povo e grandes e a relação de antagonismo, conforme ressaltado por Ames:

Muito embora os termos (adversário/inimigo; agonismo/antagonismo) sejam novos, o significado que Mouffe lhes confere é perfeitamente perceptível na obra de Maquiavel. Com efeito, para o florentino a oposição de grandes e povo é, a princípio, da ordem da relação entre inimigos. A paixão que move uns e outros é no sentido de suprimir a força contrária. $\mathrm{O}$ movimento não se conclui tão somente porque, e na medida em que, cada parte é contida pela outra no seu desejo desmesurado. Do conflito essencial emerge uma relação política na medida em que as leggi et ordini que resultam do confronto possibilitam um ordenamento político favorável a todos. A criação das leis e instituições não elimina o antagonismo; apenas o "domestica". (AMES, 2012, p. 225)

Como pode-se perceber, existem muitas semelhanças na teoria da democracia agonística de Mouffe com a teoria republicana de Maquiavel. A ideia de dissenso e conflito está intrinsecamente ligada ao propósito do agonismo, conforme Mouffe: "uma das chaves para a tese do pluralismo agonístico é que, longe de pôr em risco a democracia, a confrontação agonística é, de fato, sua condição de existência." (MOUFFE, 2005, p. 21). Assim,

o desejo de comandar dos grandes encontra no desejo de liberdade do povo seu limite ao domínio e vice-versa. Isso obriga as duas partes ao acordo: nascem dali leis e instituições capazes de dar vazão aos desejos dissimétricos de grandes e povo. É preciso ter presente ainda que esse acordo não põe fim ao conflito (ou ao antagonismo, como diria Mouffe), não é capaz de neutralizá-lo, mas apenas normalizá-lo em formas sempre precárias e provisórias. Nas categorias de Mouffe, teríamos aqui "a política”. (AMES, 2012, p. 226)

Esse confronto para Maquiavel é a base para uma república ser eficiente. É o confronto de ideias entre sujeitos que possuem humores opostos, 
incompatíveis, mas que se vêem como adversários que necessitam dos dois desejos divergentes para efetivar e manter a liberdade republicana.

Conflito é no sentido de ideias onde o dissenso é saudável. Maquiavel defende que os desejos do povo e dos grandes são naturalmente divergentes, opostos. Essa repulsa é o que mantém a liberdade. Os dois sujeitos apresentam suas ideias e defendem seus ideais; conviver nesse espaço plural é o meio que Maquiavel encontra para proteger a liberdade republicana. Conforme Ames,

o caminho sugerido por Maquiavel é o do confronto aberto das posições divergentes e a busca do que, com Mouffe, podemos chamar "hegemonia". A posição alcançada certamente implica em concessões, acordos; mas não consenso no sentido de superação ou neutralização das diferenças, pois acarreta na vitória de determinados interesses sobre outros e, portanto, na permanência do dissenso. A vitalidade da política, na visão de Maquiavel, surge precisamente da impossibilidade de aniquilar o dissenso. Em política sempre teremos vencedores e vencidos e não uma comunidade harmônica que converge racionalmente para o bem comum. No entanto, Maquiavel também nos lembra que em política - quando existem estruturas institucionais que possibilitam a manifestação do dissenso (...) - ninguém vence definitivamente: o vencido pode (e, diríamos, é salutar que aspire a) reverter sempre o resultado a seu favor. (AMES, 2012, p. 229)

Dessa forma, o dissenso proporciona o pluralismo de ideias. O direito de todo cidadão manifestar sua opinião. Esse ambiente de dissenso é plural. É como um fórum onde todas as vozes possuem espaço e divergem entre si para chegar a acordos, possibilidades de novas leis, por meio do debate que não necessariamente tem o objetivo de chegar a uma única linha de pensamento, a um consenso ${ }^{6}$. Esse é prejudicial para as repúblicas. Ele é limitador. Não dialoga com as partes. Repreende. Não evolui e não cria espaços para o diálogo. Não ouve as demandas, os significantes. As deliberações não possuem autonomia. $\mathrm{O}$ consenso é a imposição de uma Verdade. E isso não é bom para a liberdade segundo Maquiavel.

6 Luis Felipe Miguel (2014) ressalta que um dos aspectos mais marcantes - e mais surpreendentes - da teoria política das últimas décadas foi a decadência do conflito. Percepções da política e da democracia que enfatizam o valor, a necessidade e a possibilidade do consenso ganharam preeminência a partir dos anos 1980, deslocando em primeiro lugar as narrativas centradas na ideia de dominação, mas também acabando por atingir o pluralismo liberal que até então ocupava uma posição hegemônica. E o fenômeno não se verifica, como se poderia esperar, em teorias de integração social, na esteira, por exemplo, do funcionalismo sistêmico ou do behaviorismo. Está presente nas visões que se apresentam como emancipatórias e como herdeiras do pensamento crítico. 
Conforme a conclusão de Ames (2012) "A insistência no consenso e a aversão à confrontação levam à apatia e ao declínio da participação política. Mesmo que o acordo acerca de políticas seja necessário, precisa sempre vir acompanhado do dissenso" (p. 232).

A grande questão é proporcionar espaços públicos para que as deliberações aconteçam de forma que povo e grandes coloquem em pauta suas demandas. A partir daí nascem as leis que irão proteger e organizar a sociedade, ao mesmo passo que não é de todo saudável (na visão agonística de Mouffe) que se parta para esse patamar de resoluções das demandas sociais pois que:

Devido a uma esfera pública política que evita a confrontação agonística (entre adversários), o sistema jurídico é frequentemente visto como o encarregado para organizar a coexistência humana e regular as relações sociais. Na ausência do debate político, a lei é acionada para prover soluções para todos os tipos de conflito. (AMES, 2012, p. 232)

Nesse sentido, pode-se pensar em uma associação, em semelhanças, em aproximações da ideia de conflito em Maquiavel como valorização do dissenso e por consequência do pluralismo de ideias. Assim, abrem-se caminhos para se pensar em uma democracia agonística pluralista, onde os desejos dos sujeitos são colocados como pontos divergentes. Não inimigos, mas como adversários que expõe suas propostas e anseiam por mudanças que não são permanentes, mas provisórias, passíveis de reformulações, enfim hegemônicas.

Por fim, o dissenso possibilita o pluralismo, que é o lugar das diferenças. E as leis são o resultado das mais variadas demandas colocadas pelos humores opostos do povo e dos grandes. As leis que são feitas pelo povo, são uma decisão coletiva de ideias que não precisam convergir, apenas serem ouvidas para que tenham espaço. São pensamentos que são verdades, realidades de um grupo que quer ser ouvido e respeitado. O consenso é prejudicial e causa a destruição de uma república. $\mathrm{O}$ que Maquiavel deixou escrito há quinhentos anos é hoje estudado por Chantal Mouffe e outros autores de outras formas. São novas teorias, diferentes termos, mas a essência é a mesma. Agonismo implica conflito. E esse é dissenso, que só pode ter vida se for plural. 


\section{REFERÊNCIAS}

\section{PRIMÁRIAS}

MAQUIAVEL, Nicolau. O Príncipe. São Paulo, Martins Fontes; 2010.

Discursos sobre a primeira década de Tito Lívio. São Paulo, Martins Fontes; 2007.

. História de Florença. São Paulo, Martins Fontes; 2007.

Tutte le opere: storiche, politiche e letterarie. A cura di Alessandro

Capata. Roma: Grandi Tascabili Economici Newton, 1998.

MOUFFE, Chantal. Democracia, cidadania e a questão do pluralismo. Política \& Sociedade. Florianópolis, n³, p. 11-26, 2003. Disponível em: <https://periodicos.ufsc.br/index.php/politica/article/viewFile/2015/1763 > Acesso: 10 fev 2015

MOUFFE, Chantal. Por um modelo agonístico de democracia. Revista de Sociologia e Política. Curitiba, n.25, p.11-23, nov. 2005. Disponível em: $<$ http://www.scielo.br/scielo.php?script=sci_arttext\&pid=S010444782005000200003> Acesso: mar 2011

MOUFFE, Chantal. En torno a lo político. México, Fondo de Cultura Econômica, 2009.

LACLAU, Ernesto; MOUFFE, Chantal. Hegemonia y estrategia socialista. Hacia una radicalización de la democracia. Madrid, Siglo XXI, 1987.

\section{SECUNDÁRIAS}

AMES, José Luiz. Republicanismo conflitual e agonismo democrático pluralista: um diálogo entre Maquiavel e Chantal Mouffe. Princípios - Revista de Filosofia, Natal, v. 19, n³1, p. 209 - 234, 2012. Disponível em: $<$ http://dialnet.unirioja.es/servlet/articulo? codigo $=4064869>$ Acesso: $11 \mathrm{fev}$ 2015

BERLIN, Isaiah. Quatro ensaios sobre a liberdade. Disponível em: $<$ http://www.institutoliberal.org.br/conteudo/download.asp?cdc=905> Acesso: 20 jun 2011

BIGNOTTO, Newton. Maquiavel Republicano. São Paulo, Loyola; 1991. 
CASTEL, Karen. O Povo em Maquiavel como Guardião da Liberdade. Dissertação, UFPEL, 2013.

CONSTANT, Benjamin. Da liberdade dos antigos comparada à dos modernos. Revista Filosofia e Política, Porto Alegre, n² 2, p. 9-25, 1985. Disponível em: $<$ http://caosmose.net/candido/unisinos/textos/benjamin.pdf > Acesso: 10 jan 2011.

MENDONÇA, Daniel de. Teorizando o agonismo: crítica a um modelo incompleto. Revista Sociedade e Estado, v. 25, n 3, 2010. Disponível em: $<$ http://www.scielo.br/scielo.php?script=sci_arttext\&pid=S010269922010000300004 > Acesso: 10 fev 2015

MIGUEL, Luis Felipe. Consenso e conflito na teoria democrática: para além do “agonismo". Lua Nova, São Paulo, v. 92, p. 13-43, 2014. Disponível em: <http://www.scielo.br/pdf/ln/n92/a02n92.pdf > Acesso: 11 fev 2015

PETTIT, Philip. Republicanismo Una Teoria Sobre La Libertad y El

Gobierno. Barcelona, Paidos Iberica Ediciones; 1999.

SILVA, Ricardo. Maquiavel e o conceito de liberdade em três vertentes do novo republicanismo. Revista Brasileira de Ciências Sociais, Vol. 25, n 72, p. 37-58, fevereiro/2010. Disponível em:

http://www.scielo.br/pdf/rbcsoc/v25n72/v25n72a04.pdf Acesso: 15 set 2011.

. Da honra ao patrimônio: conflito social e instituições políticas nos Discorsi de Maquiavel. Revista Brasileira de Ciência Política, nº 12, p. 43-66, set/dez. 2013. Disponível em:

http://periodicos.unb.br/index.php/rbcp/article/view/9847/7216 Acesso: 04 ago 2014.

SKINNER, Quentin. As fundações do pensamento político moderno. São Paulo, Companhia das Letras; 2009.

WINTER, Lairton. A teoria dos humores de Maquiavel: a relação entre o conflito e a liberdade. Cadernos de Ética e Filosofia Política 19, p. 43-75, 2011. Disponível em: www.revistas.usp.br/cefp/article/download/55738/59154 Acesso: 01 ago 2014. 


\section{TEORÍA DEL CONFLICTO EN MAQUIAVELO Y EL AGONISMO EN CHANTAL MOUFFE: POSIBLES CONEXIONES}

Resumen: La investigación se propone hacer un análisis de dos categorías: el conflicto de Maquiavelo, en el sentido de un choque de deseos de ser saludable para la república y el modelo de la democracia agonística demostrado por Chantal Mouffe que se relaciona con la idea de transformar el enemigo in adversario. Su objetivo es comprobar en qué medida se acercan a estas ideas y/o fuera de sus significados. La metodología se basa en la base teórica de algunos autores que ha estado trabajando este tema, como José Luiz Ames y Luis Felipe y Miguel autores que trabajan la idea de conflicto en Maquiavelo. Por último, tenemos la intención de mostrar que hay elementos de la teoría maquiavélica presente en las categorías de análisis dilucidados de Chantal Mouffe, lo que puede contribuir a la discusión de las teorías de la democracia.

Palabras clave: Estrategia. Táctica. Planificación Estratégica. Política. Guerra.

\section{MAQUIAVELLI'S CONFLICT THEORY AND THE AGONISM OF CHANTAL MOUFFE: POSSIBLE CONNECTIONS}

The research proposal is an analysis about two categories: Machiavelli's conflict, in the sense of a confrontation of desires as being something healthy for the republic and the agonistic model of democracy demonstrated by Chantal Mouffe that is linked to the idea of transforming the enemy in adversary. It is intended to ascertain to what extent these ideas approach and/or distance themselves in their meanings. The methodology is based on the theoretical contribution of some authors who have been working on this subject, such as José Luiz Ames and Luis Felipe Miguel, as well as authors working on the idea of Machiavelli's conflict. Finally, we intend to show that there are elements of the Machiavellian theory present in the analytical categories elucidated by Chantal Mouffe, who can contribute to the debate of the theories of democracy.

Key words: Strategy. Tactics. Strategic planning. Politics. War. 